\title{
A STYLISTIC ANALYSIS OF THE CACAXTLA MURALS
}

\author{
Stanley L. WaLling JR. \\ Tulane University, \\ New Orleans
}

This paper is a discussion of the nature of the style of the recently discovered Pre-Columbian murals at the site of Cacaxtla in the state of Tlaxcala, Mexico. Descriptions of these murals have been published by members of the Proyecto Mexicano-Aleman which has carried extensive research in the Puebla and Tlaxcala regions (see for example D. Molina and D. Molina, 1977; M. Molina, 1978; Schmidt 1976). This discussion will center upon an examination of the general style of the murals - this includes the overall structure of the representations, the nature of the portrayal of depth, the manner of creation of form and general spatial composition. This analysis of style, as well as a brief description of the iconography will permit a comparison of the Cacaxtla paintings with other Pre-Columbian murals from the Maya and Mexican areas. This in turn will allow for examination of stylistic affinities between these Highland Mexican works and known Pre-Columbian artistic areas, and a determination of the probable stylistic source for these murals.

The Cacaxtla paintings are located in site T-280 of the Tlaxcala region which Cook (1974: 14) has interpreted as a Classic Period fortified hilltop structure. Diana and Martha Molina use ceramic and architectural features, as well as representations from the Late Classic Gulf Coast region, Yucatan and especially highland Mexico as comparative material to determine a late Classic date for the two groups of Cacaxtla murals (D. Molina 1976: 463, 1977: 3, M. Molina 1976a: 321).

The lower group of murals is located in Building $\mathrm{B}$ at the site and consists of a battle scene (Figure 1). This scene is not quite 21 meters in length and is divided into two sections by a staircase. The painting on the talud east of the staircase extends for 12 meters 
and the talud decoration on the western side extends for 9 meters. A thin painted band marks the lower and far right boundary of the eastern section of the mural. The western section however has only a band at the base - no vertical bands remain to separate the painting from surrounding wall space.

Forty-seven figures are represented in this mural, twenty six of whom are on foot and the remainder seated or prostrate (Ruiz, 1979: 149). Most of the figures, especially those directly involved in the battle are shown in profile or near-profile and have active poses and highly expressive facial features. These active figures wear feathered headgear, ornate collars and elaborate loin cloths. Many of the active figures wear highbacked Maya style sandals and all carry feathered shields and brandish spears or knives. The reclining and prostrate figures are representations of wounded or dead warriors. For the most part they wear less clothing than the active figures and what clothing they do wear (feathered headresses, collars, bracelets and anklets) is less elaborate than that of the standing figures. These figures can be grouped into units of figures (Ruiz, 1977: 149). Most of these units consist of interacting figures - at least one triumphant warrior directing his gaze at one or more wounded or dead foe who are located at his feet. Two units consist of single figures - one on the eastern talud and the other on the western section. These figures stand erect and are shown frontally with toes pointing outward. Both wear highly complex feathered dress and elaborate sandals. The eastern figure has been wounded by a spear in his left cheek, but neither figure holds weapons or a shield, nor takes direct part in the fighting. They stand aloof and stationary in the midst of battle. The western figure seems especially distant from the carnage. He stands with arms crossed at the wrists and is surrounded to a large degree by an outlined background decorated with half-stellar motifs. Unfortunately color reproductions of this mural are not yet in print. Unpublished photographs indicate that the figure and background of the battle scene are primarily blue. Well executed line drawings do exist (see especially M. Molina, 1978) and these reveal the relative positions, poses, gestures, interrelations and general disposition of the figures.

In Building $\mathrm{A}$, on a higher section of the same structure complex in which the Battle Scene is located, the second group of Murals can be found. The color scheme for this mural group is partially published. A color plate on the cover of INAH Bulletin Number 16 indicates the color scheme of the upper section of the southern 
portico mural. Also, a brief description of the color scheme of all the murals in Building A is given by Schmidt (1976: 25) who indicates that 8 principal colors were used in these paintings. Schmidt reports the colors of some of the major visual elements - he describes the color of the figures and the background in the northern wall painting (Figure 2) as being primarily black and red respectively. The northern jamb figure (Figure 3 ) is also primarily black. The southern jamb and wall figures both wear yellow leopard skins with black spots. Complete analysis of color will be possible only when researchers publish color reproductions of all the Cacaxtla murals.

These murals of the upper structure are located in the portico and the jambs of a building which was superimposed on the lower and earlier Building B (Ruiz, 1979: 149). This higher group of murals consists of two murals flanking a central opening in the rear wall of the portico. Two additional murals are located on the jambs of this opening. Beyond this opening, in the adjoining room, are traces of murals so faded as to be illegible. Both the jamb and the portico mural are each about 1.8 meters high. The wall murals are about 2.2 meters in width and the much narrower paintings in the opening cover the width of the jamb. Unlike the battle scene these murals each consist of depictions of single figures. The figures here are characterized by less gesture, expression and movement than exists in the painted figures of Building B.

The northern jamb mural is an upright human shown with a frontal body and profile face. His torso and face are directed slightly to his right (toward the wall on which the larger murals are painted), and he wears a leopard costume that reveals only his face. His arms and legs end in claws. It is unclear whether these representations of claws depict part of the ceremonial dress or the actual form of this figure. Unlike some representations of clawed figures from Teotihuacan, the human feet beneath this figure's foot gear are not depicted. The legs are shown in profile with claws pointing outward away from the body. The Jaguar figure holds in his right arm a vase from which liquid is pouring, and in his left hand a live snake. He wears an elaborate feathered headgear, a collar, bracelets, a belt, a highly decorated loin cloth, ornate knee decorations and calf straps. The figure appears to stand in front of a section of low border decoration.

The individual depicted in the southern jamb (Figure 3) like the northern jamb figure has a frontal body and profile face. This 
southern figure stands with legs crossed, poised on his toes and holds in his right arm a large conch from which emerge decorative scroll elements. On the left side of his body below the conch a red-haired human figure can be seen. The figure is characterized by a frontal torso and a profile face which is directed to the main figure's left. The small figure wears a bracelet on his one exposed arm as well as a collar. The main figure also wears a collar. He has ornately decorated hair which hangs from his head to his feet. $\mathrm{He}$ wears a lengthy, leopard skin pattern loin cloth, as well as bracelets, knee decorations, and high-backed sandals. He stands in front of a ground level border containing a snake, turtle, and linear decorative elements.

Both the southern and the northern wall paintings show single human figures holding in their arms large ceremonial bars. The southern figure faces to his left and the northern figure to his right. Thus, the two figures face each other across the opening in the wall. Both of these portico figures have frontal legs and torsos and profile heads. Toes in both figure are directed outward, away from the body. The large ceremonial bars which both figures support in their arms are oriented downward in the direction of the opening in the wall. The figures each stand on a serpent which faces in the same direction as they do, and whose body stretches across the top of the lower decorative frame and extends up the opposite side of the mural. The serpent in the northern painting is decorated with a leopard skin motif, like the dress of the central figure. The hands and feet of this central figure end in claws. Only his profile right eye, nose and mouth can be seen. On his shoulders he wears elaborate feathered apparel and on his waist he wears a highly ornate loin cloth with hanging decorated textile bands. Straps adorn his calves. A decorative band of diagonal and horizontal linear patterns as well as marine shells, snakes and turtles is located on the border below and to the right of the jaguar figure.

A similar band of decoration borders the panel on the base and left side of the southern portico figure (Figure 2). His skin is black. He wears an elaborate headress in the shape of a bird's head. Long curving feathers extend from his shoulders and arms. He wears a belt, a loin cloth with attached cape and has foot gear which are tied at the ankles and end in large bird claws. He stands on a feathered serpent and like his jaguar counterpart faces the remnants of a stylized maize plant that is now covered partially by relief decoration.

These murals from Building $\mathrm{A}$ as well as the Battle scene from 
Building B (Figure 1) will be compared here with murals from other Mesoamerican sites. Extant Classic Period and Post-Classic murals are found in Mexican and Maya regions. The Maya murals to be examined here include examples from Bonampak (Ruppert, Thompson, and Proskouriakoff, 1955). Chichen Itza (Morris, Charlot, and Morris, 1931; Figure 159), Uaxactun (Smith, 1950: Figure 46), Tzula (Thompson, 1904: Plate II) and Chacmultun (Merwin and Vaillant, 1932: Plate VIII). Because the Maya area was heavily influenced by highland Mexican aesthetic principles by the time of the Late Post-Classic Period (for example, see Robertson, 1970 for a discussion of the use of Mixtec style in Post-Classic Tulum paintings) the Maya murals from the Yucatecan from this time will be grouped with Mexican works. These Mexican, or Mexican influenced murals are from Teotihuacan (Miller, 1973 and Sejourne, 1966) Tulum (Lothrop, 1924: Figure 7), and Santa Rita (Gann, 1900).

Some scholars maintaing that Cacaxtla murals are closer stylistically to the Mexican materials than they are to the Maya pieces. For example the foremost scholar of the Cacaxtla paintings, Martha Molina as well as other researchers have asserted that the murals from Cacaxtla represent the work of Mexican artists working in a Mexican artistic tradition which has been only slightly influenced by Maya stylistic patterns (for example, D. Molina, 1977; M. Molina, 1976a, 1978; Ruiz, 1979; Schmidt, 1976; and Vivanco, 1980). According to Molina (1976a: 322) one important consideration in the determination of the culture source for the paintings is the fact that there are no Maya glyphs associated with the figures on the Cacaxtla murals. Because of this Molina believes that the murals must be the work of highland Mexican artists. I believe this lack of Maya glyphs in the Cacaxtla paintings may be explained by the cultural context of the murals. Even if they were painted by an artist working in the Maya tradition there probably would have been no call for Maya hieroglyphs in a Mexican site. Because the murals would have had meaning only for the Mexican patrons and not the painter which the Mexicans sponsored, it is entirely reasonahle that Mexican and not Maya glyphic figures should accompany the figures. ${ }^{1}$

1 It should be noted that after the completion of this paper, I had the opportunity to read the draft of a paper by Donald Robertson ("The Cacaxtla Murals" which will appear in the papers of the Fourth Mesa Redonda de Palenque, to be published by the University of Texas Press) in which he discusses at length the possibility if the use of Maya painters in Cacaxtla by Mexican patrons. 
Another consideration in the determination of the stylistic source is the fact that the mural paintings themselves are the only evidence of Maya culture in Cacaxtla (M. Molina, 1976a: 322 and Cook, 1974). The current climate of opinion seems to support the belief that if the Cacaxtla paintings were actually the result of the hand of a Maya artist they would be accompanied in the archaeological record by additional evidence of Maya culture, such as linguistic diffusion and plastic arts remains. It has been argued that commercial contact alone could account for traits such as the Maya physical features of the figures. However, the afore-mentioned lack of Maya plastic arts in the archaeological record does not support this belief in commercial contact.

Also, it has been argued that this lack of additional archaeological or linguistic evidence of Maya contact indicates a very general and indirect influence, probably via the Gulf coast culture area (D. Molina, 1977: 3; M. Molina, 1978: 103; Schmidt, 1976: 31; and Vivanco, 1980: 214). I believe that this interpretation is the opposite of what the evidence indicates. If Maya style did influence Cacaxtla artists indirectly then it seems entirely likely that the effect would have been broad rather than specific. A very general indirect influence from the Maya area would have affected a number of arts instead of one. If the assumption of indirect influences is correct then a diffuse Maya style should be seen in a number of arts at Cacaxtla — such as ceramic decoration and small sculpture- instead of in painting alone. The believers in this indirect contact rule out the possibility of the design and execution of the murals by a Maya artist. It is precisely because the Maya influences occur in such a clear and strong fashion in only one very limited area of decoration that the murals should be considered potentially as examples of Maya painting. This existence of Maya style only in painting probably indicates contact of limited duration, but not of limited intensity, between the Maya and Cacaxtla peoples. Possibly the paintings were done by an artist (or artists) trained in the Maya artistic tradition of Yucatan who worked in Cacaxtla for only a short time and did not influence other arts. The interpretation which stresses Gulf coast contact unnecessarily rules out the possibility of the existence of a mobile artist of the type that Robertson (1970) hypothesizes for the Post-Classic Maya and Mixtec peoples, who used his native art style in works done for foreign patrons.

Another point which relates to cultural context is the corpus of iconographic material on the murals. Some researchers have pointed 
to a number of iconographic elements common to both Teotihuacan and Cacaxtla as evidence of Mexican style in the Cacaxtla murals. It should be noted that a number of these iconographic elements such as the Quetzal bird, plume serpents, aquatic elements, and jaguar figures are well-known in the Maya area. More important however is the fact that the iconographic motifs are for the most part ancillary elements in the determination of the artistic style. An example of this point of view can be seen in the work of Friedrich (1970) who used ethnographic analogy to determine a hierarchical analytic framework for stylistic analysis. This framework assumes decorative techniques and iconographic motifs are the elements which diffuse most easily between groups in direct or indirect contact. The structure of these techniques and motifs, that is the basic artistic style however does not diffuse easily. Spatial compositional rules and patterns which govern the structural relationships of decorative elements are not likely to be transferred to another group. Thus, a similarity in overall basic style is assumed to be indicative of contact much more intensive that would occur in an indirect system such as the long distance commercial network with the Maya region which has been hypothesized for the Cacaxtla site. The motifs which have been emphasized as indicative of the Cacaxtla style are in fact essentially iconographic and not the hallmarks of a painting style. The analysis of style which is to follow will examine patterns of spatial relationships of elements, overall decorative structure, modeling of form, standards of proportion, and portrayal of depth.

A sense of depth in the Maya murals is created through complex overlapping of figures as in the battle scene at Bonampak or by the placement of more distant figures higher than closer ones in the composition, such as occurs in the mural from Chichen Itza. In both of these examples the sense of depth is heightened by the activity of the figures portrayed. The figures often appear to be in the process of turning in space. For example, the participants in the Bonampak battle scene appear in profile, frontal and threequarter views and create a sense of receding space. No such sense is created by Mexican representations. The Mexican figures do not seem to move. They stand in rigid, stylized poses. Depth occurs only through fairly simple overlapping. In the Santa Rita mural for example, the relative position of the profile figures' limbs can only be determined by understanding the pattern of overlapping. Figures 
are not shown turning in space nor are more distant figures shown at a greater height in the mural.

Use of space also varies between the Mexican and Maya materials. In Classic Maya murals the bands which delineate the separate registers tend not to be much greater than the height of a figure's head, as they are in the Chacmultun and Uaxactun murals. The Maya representations are often characterized by open space between figures (see for example the murals from Tzula and Chichen Itza) and the spatial composition is such that a subtle rythm of open and "closed" space draws the eye neatly across the mural registers. This visual rythm is especially evident in the non-battle scenes at Bonampak, the mural at Uaxactun, as well as the Tzula and Chacmultun paintings.

No such rythm exists in the Mexican paintings. The Mexican murals are characterized by a horror vacui. Open space is filled to such a degree that the figures appear to crowd each other. In the Maya murals the open space between persons is often equal to or greater than the width of the human figure. In the Mexican works, such as the Tulum and Santa Rita murals, open space is often far narrower than the width of a normal individual. In addition, the murals at Teotihuacan, Tulum, and Santa Rita have register boundaries that are up to twice the height of a normal figure's head.

Other stylistic differences between Mexican and Maya mural painting exist in the presentation of the human form. Maya human forms tend to be unified in general structure. That is, the points of articulation of the limbs with the torso are rounded and nonsegmented. One continuous line seems to be all that is needed by the artist to define the human form - limbs and other body parts do not tend to be visually delineated as separate units. The body is in effect a visual "whole". The Maya view of the human body tends to be primarily perceptual. The human form is shown much the way the artist viewed it - forms tend to approximate their natural appearance. Part of this natural appearance is the standards of proportion used in the human figure. Height for normal standing figures ranges between the length of $51 / 2$ and 7 heads. Also natural in appearance is the slight sense of volume in form created by rounded body surfaces, curves in representations of clothing that define underlying human form and active gesturing poses. These features and the others treated in this section can be found in all of the Maya mural examples discussed here.

In Mexican murals, on the other hand, the human form tends 
to be flat in overall appearance. Gesture is stylized to such a degree that it does not create a sense of space around figures, and because depth is created by use of overlap alone the human form has no appearance of volume. Examples are murals such as the Teotihuacan and Santa Rita paintings. Furthermore, figures in these murals are highly conceptual in style. They are generally characterized by visual patterns which symbolize larger, more complex forms - for example, a few stylized strands atop a figure's head will signify a full head of hair. These conceptual forms are highly unitary - the body is composed of separate outlined elements. As a result, the human form is compartmentalized. Points of body part articulation are characterized by segmented outlining which slows the movement of the viewer's eye across the figure. The observer's eye tends to "jump" from separate visual element to visual element in the process of defining a complete human form. In addition, the relative proportions of the components of this human form are far different than those of the Maya representations. Mexican forms vary in height between $21 / 2$ and $41 / 2$ times the height of the head (Robertson, 1959, Chapter 1).

This difference in proportion and the other differences in representation noted here indicate two different aesthetic traditions in aboriginal Mesoamerican mural painting. Clearly, the Cacaxtla paintings are within the Maya stylistic tradition. The Cacaxtla mural proportions are between slightly under and slightly over 7 head heights tall; figures are unified in overall form: there is no horror vacui; representations are perceptual and unified rather than conceptual and unitary; figures create an impression of volume and strike active, fluid poses; the width of the decorative band does not in any case far exceed the height of a head of a normal figure; and the spatial composition (of the Battle Scene) suggests the rythmic pattern of alternating open and closed space noted in Uaxactun, Bonampak, Tzula and Chacmultun paintings. These Maya stylistic traits in the Cacaxtla paintings indicate that the painters of these murals were trained specifically in the Maya tradition. The manner in which the artists structured their compositions indicate an intimate knowledge of Maya standards of representation. No indirect Maya "influence" by way of the Gulf coast that some researchers postulate could account for this familiarity with things Maya.

In addition to the use of stylistic analysis to help determine difference between artistic traditions, one may also use stylistic analysis to determine differences between representations of similar 
iconographic motifs. I believe this latter use is of interest in the analysis of the paintings in Building $\mathrm{A}$. The jamb paintings and portico mural of Building A exhibit subtle but significant differences in the handling of conceptual space by the ancient artists. I believe that these differences indicate that the artist who created the jamb representations had greater control of visual space than the creator of the larger murals on the rear wall of the portico. The difference between these two groups of paintings can be seen in a number of features. For example, the waist decorative elements in both jamb representations curve around the front of the body and turn inward as they move around the back of the torso. Not only is the curving across the waist here greater than it is in the larger portico representations, but these larger forms do not have belts that curve inward toward their backs. The northern and southern portico murals thus seem less modeled and somewhat more two-dimensional than their smaller counterparts on the jambs. A similar high degree of curving of elements around the body can be found in both the knee and ankle decorations of the jamb personages.

An additional point is the fact that on the jamb representation of the jaguar figure the waist band and knee decorations curve in the opposite direction on the ankle bands. The sides of these ankle decorations are pointed downward, whereas the sides of the knee and waist elements are directed upward. It appears that the artist was trying to account for the difference in perspective created by elements seen by a stationary observer at different ends of a quasicylindrical form (that is, the human body) - unfortunately, this attempt at perspective by the artist of the jambs is not successful. The ends of a horizontal line on a cylinder when seen from above appear to curve upward, as the lines of the jaguar figure's belt and knee bands do. When seen from below a similar horizontal cylindrical line will appear to have sides that bend downward as the lines of the ankle bands do. Thus the eye level effect created by the lines in this figure is inconsistent. The jaguar figure appears to be seen simultaneously from two points of observation - one above the figure and one below. A consistent eye level would have been created by a curving of waist and ankle lines in directions opposite to the ones in which they appear. If the sides of the figure's belt pointed downward and the sides of the ankle band were directed upward the visual effect of a single eye level would have been created. Despite this inconsistency in perspective there is clearly more of an attempt at defining a realistic perspective here than in the portico 
paintings, where elements are all curved upward and appear as though they should be seen from above, even though the figures are at eye level. This degree of curving in the jamb figures created not only a sense of the specific location of ankle, knee and waist bands above and below eye level, as well as visual depth, but also a greater sense of mass. The viewer of both, the northern and southern jamb figures, gets a distinct impression of the weight of the knee decorations and waist elements. He can see them slump slightly over the hip bones and under the knees of these two elaborately dressed persons.

The jamb figures are also characterized by a greater and more delicate overlapping of visual elements. For example, the upper feathers in the jaguar figure's headress* appear to turn away from the viewer and the point back toward the figure as they fall across the shorter and more stable feathers of the lower headress. Here the representation almost suggests the use of foreshortening. The modern observer is given a sense of the relative weight and position of these feathers and a view of how they might have been arranged in space on an ancient head piece. The feathers on the northern portico mural however are carefully measured and stylized. They overlap one another precisely and continuously and provide no sense of great depth or movement. Similarly, the feathers that decorate the shoulder of the jaguar figure in the southern wall painting show depth through overlap alone. Although they are detailed in form they seem almost disassociated from the figure's body. They appear to hang in space without mass or appreciable depth.

Another point of interest with respect to the jamb representations is the fact that the feathers of the headress of the northern figure and those on his knees are arranged so as to suggest activity. The painter here appears to have caught a "moment" in a sequence of movement. The knee and headress elements are not alone in indicating this sense of movement. For example, water is being poured from an upturned vase in the figure's right arm, and a partially coiled live snake is held to the side. Note that this snake is much more naturalistic and animated than the rigid serpents in the portico representations. The viewer can feel the jaguar man turning the vase as he pours the water in one arm and delicately holds the coiling snake in the other. In the southern jamb the central individual stands with legs crossed as though caught in

\footnotetext{
* Jamba norte.
} 
the act of dancing or stepping very lightly. Like the jaguar figure, his torso is angled in the direction in which he is looking, but unlike the jaguar figure this black person's legs too are angled. It appears as though his whole body is moving in one direction.

The sense of movement here contrasts strongly with the impression created by the portico paintings. The portico figures appear solid and rounded but do not seem mobile. They stand stiffly in space while holding large ceremonial bars. Their torsos are bent and drops of water fall from one of the staffs, but no direction or specific movement are implied by the stance or by gesture. They each stand squarely above their respective serpents and are clearly anchored to one spot by the surrounding border elements and decoration. In effect they appear as stable and unmoving as the surrounding glyphic elements. Also, it should be noted that despite the apparent solidity of these portico figures neither is characterized by a sense of mass. The weight of neither figure is clearly supported by the serpent figure beneath him. Note for example that the claws on the feet of the bird figure in the portico painting do not disrupt the linear pattern of the serpent's feathers. Instead the clawed feet, and thus the whole figure, seem to "float" slightly above the serpent and the border.

On the other hand, we find an emphasis of movement and mass in the jamb figures. For example, in the southern jamb mural both activity and a sense of body weight are suggested by the figures stance and toes. The figure's toes are bent in a manner which suggests the momentary act of supporting his mobile weight. Also, the figure's loin cloth appears to be caught in the act of swinging between his legs. In the northern jamb the jaguar man stands squarely on the lower border element. His weight seems to be resting on the lowest section of border area. He does not "float" above the base as the portico figures do. Instead he appears to be securely supported by a solid floor-line. Both of these jamb persons are located to a large degree in front of the lower border sections. They are not limited in form or movement by the existence of the border. This border runs only along the bottom of the jamb representations - there is no vertical border of the type that exists in the portico murals. In the jamb representation the border no longer seems an integral part of the representation. The border is to a degree covered by the central figure. It does not exist in the same plane as the primary figures, nor does it delimit the primary decorative space. The border seems as though it were a stylized remnant of 
a decorative element that once had greater importance in defining visual space.

The high degree of control of space by the artist who created the jamb figures has been indicated by a number of factors: greater and more delicate overlap of decorative elements (for example the jaguar figure's feathers, and the border elements), greater modeling of body form (for example the highly curving waist band and other decorative elements), an attempt at perspective control (the downturned and upturned waist and ankle elements), a possible attempt at greater depth through foreshortening (the jaguar man's curved upper feathers), a distinct sense of mass (for example, the greater roundness created by the highly curved decorative elements, the realistic manner in which the belts sit on the hip bones and the bent toes of the figure holding the conch), the impression of movement (for example, the animated stance of the southern jamb figure, the orientation of this figure's torso and legs, his bent toes, crossed legs and his swinging waist cloth, as well as the northern figure's curved feathers and the live, partially coiled snake). These factors contrast greatly with the characteristics of the portico figures who are less mobile, seem to have less of a sense of mass and are more rigidly defined in space by surrounding decorative elements.

This difference in overall control of space in the two mural groups of Building $\mathrm{A}$ indicates not only the hand of two different artists, but probably a difference in the dates of the execution of the paintings. I doubt that the two styles here are evidence of the activities of two different painters at the same time. It seems unlikely that the more highly skilled painter would have been given the task of painting the less visable jamb figures while an artist of lesser skill painted the larger portico murals.

It is likely that the large portico murals were painted first and the jamb figures later by a more proficient artist. Assuming that Ruiz (1980: 150) is correct in attributing an early date to the Battle Scene, this last analysis indicates the possibilty of three periods of Maya presence at Cacaxtla - the first period for the painting of the Battle Scene in Building B, the second for the portico figures in Building $\mathrm{A}$, and the last for the painting of the jamb figures.

To account for this presence of representatives of Classic Maya culture in the Mexican highland at separate points in time, students of aboriginal Mesoamerican culture will have to alter assumptions about the degree and character of interaction of prehistoric Central American cultures. Perhaps the greatest challenge Cacaxtla provides 
researchers is the construction of new questions about basic culture patterns in ancient America. For example, did culture groups interact regularly on a long distance basis for other than trading purposes? If so, what cultural mechanism could account for this interaction? And, how can this interaction be further defined and documented in the archaeological, ethnohistoric and art historical records?

\section{REFERENCES CITED}

Foncerrada de Molina, Marta

$1976 a$ "La Pintura Mural de Cacaxtla". Proceedings of the 42nd International Congress of Americanists, volume 7: 321-329.

$1976 b$ "La Pintura Mural de Cacaxtla, Tlaxcala". Anales de Investigaciones Estéticas 45: 5-20.

1978 "Reflexiones en torno a la pintura mural de Cacaxtla". Proyecto Puebla-Tlaxcala, Comunicaciones 15: 103-107.

Friedrich Margaret H.

1970 "Design Structure and Social Interaction: Archaeological Implications of an Ethnographic Analysis". American Antiquity 35: $332-344$.

Gann, Thomas

1900 "Mounds in Northern Honduras". Bureau of American Ethnology, 19th Annual Report, Part 2: 661-692.

GARCíA CoOK, A.

1974 "Una secuencia cultural para Tlaxcala". Proyecto Puebla-Tlaxcala, Comunicaciones 10: 5-22.

Lombarto Ruiz, Sonia

1979 "Contribución del estudio de la forma a la iconografía de los murales de Cacaxtla". Proyecto Puebla-Tlaxcala, Comunicaciones 16: $149-151$.

López de Molina, Diana

1976 "Cacaxtla": Los murales y la investigación arqueológica". Proceedings of the 42nd International Congress of Americanists, volume 7: 463-466.

López de Molina, Diana and Daniel Molina

1977 "Los murales prehispánicos de Cacaxtla". Instituto Nacional de Antropología e Historia, Boletín 16: 3-8.

Lothrop, SAMUeL K.

1924 Tulum: An Archaeological Study of the East Coast of Yucatan. Carnegie Institution of Washington, Publication 335, Washington.

Melgarejo Vivanco, José Luis

1980 "Una pintura mural en Cacaxtla, estado de Tlaxcala". Cuadernos Antropológicos 2: 214-221.

Merwin, Raymond E. and George VaIllant

1932 "The Ruins of Holmul, Guatemala". Peabody Museum of Archaeology and Ethnology, Memoirs, volume 3, number 2.

Miller, Arthur G.

1973 The Mural Painting of Teotihuacan. Dumbarton Oaks, Washington, D. C. 
Morris, Earl H., Jean Gharlot and Ann Morris

1931 The Temple of the Warriors at Chichen Itza, Yucatan. Carnegie Institution of Washington, Publication 406, Washington, D. C.

Robertson, Donald

1959 Mexican Manuscript Painting of the Early Colonial Period. Yale Historical Publications, History of Art 12, Yale University Press, New Haven.

1970 "The Tulum Murals: The International Style of the Late PostClassic". Proceedings of the 38th Meeting of the International Congress of Americanists, Volume 2: 77-88.

Ruppert, Carl, J. Eric Thompson and Tatiana Proskouriakoff

1955 Bonampak, Chiapas, México. Carnegie Institution of WashingSchmidt, Peter ton, Publication 602, Washington, D. C.

1976 "El Mural del Palacio, Estructura 11-1 del Sitio T-280 Ca. caxtla". Proyecto Puebla-Tlaxcala, Comunicaciones 11: 23-49.

Sejourne, Laurette

1966 Arquitectura y pintura en Teotihuacán. Siglo Veintiuno Editores. Mexico City.

Smith, A. Ledyard

1950 Uaxactun, Guatemala: Excavations of 1931-1937. Carnegie Institution of Washington, Publication 588, Washington, D. C.

Thompson, Edward H.

1904 Archaeological Researches in Yucatan. Peabody Museum of Archaeology and Ethnology, Memoirs, volume 3, number 1.

1976 Tiempo: Seminario de la vida y la verdad 68 (number 1719): 5. 


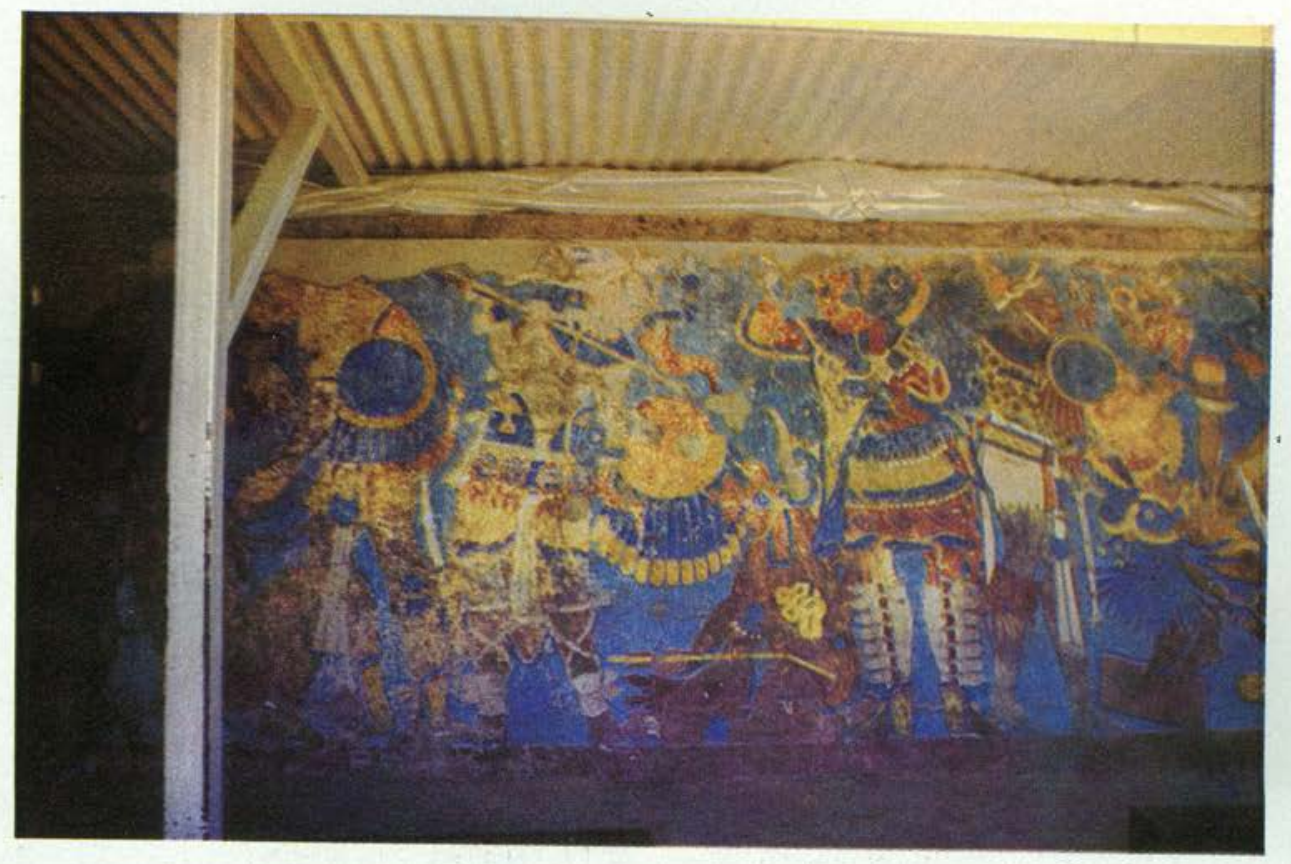

Figura 1. Detalles del Mural de la Batalla (Fotos Ana Luisa Izquierdo)

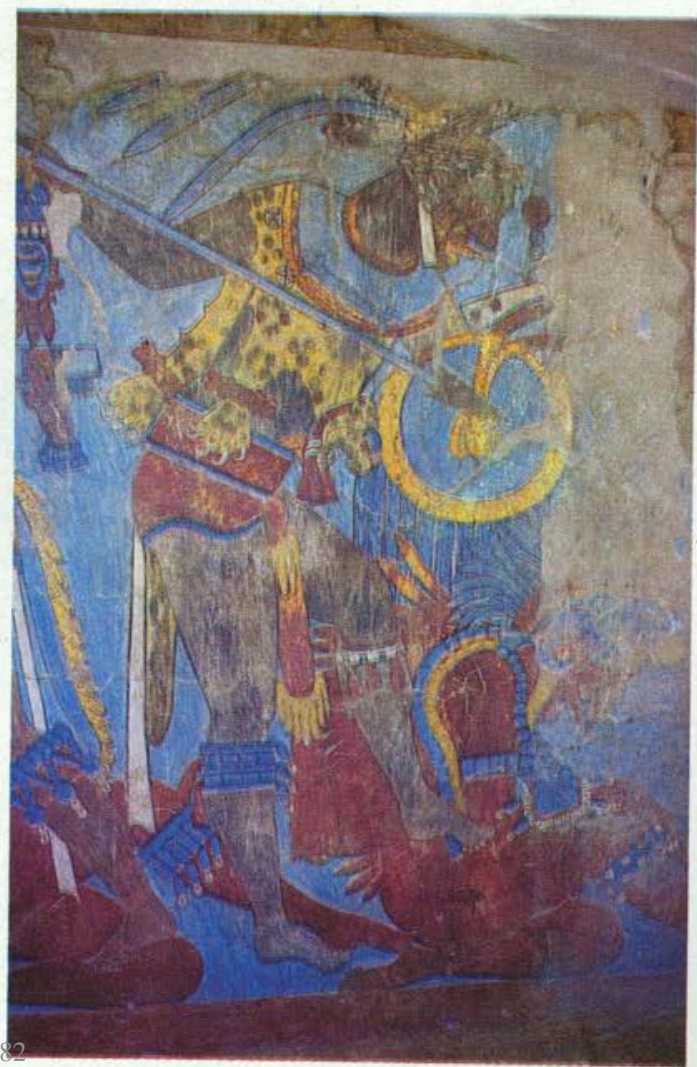

Estudios de Cultura Maya. Vol. XIV, 19 Instituto de Investigaciones Filológicas/ Centro de Estudios Mayas, UNAM 


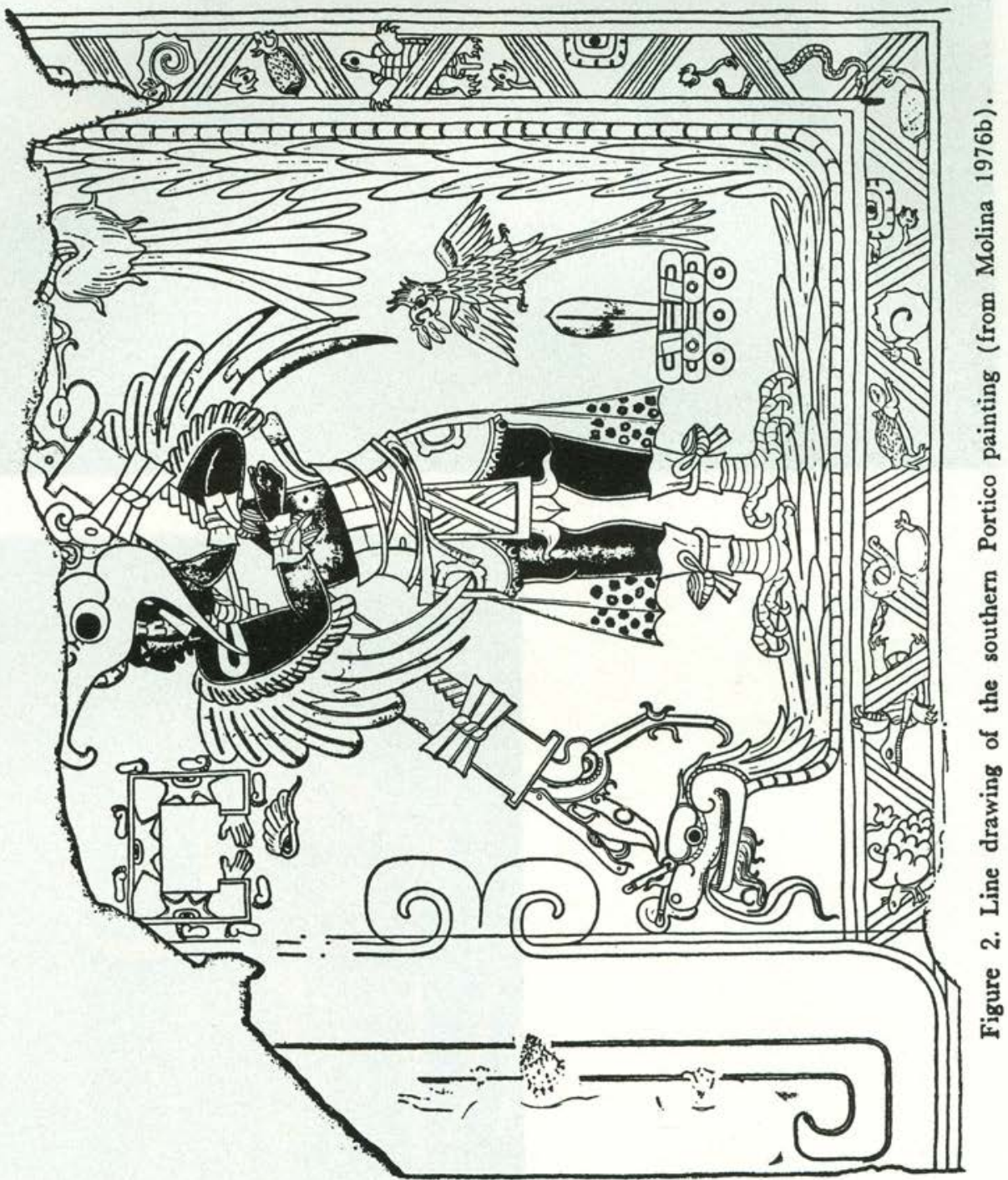




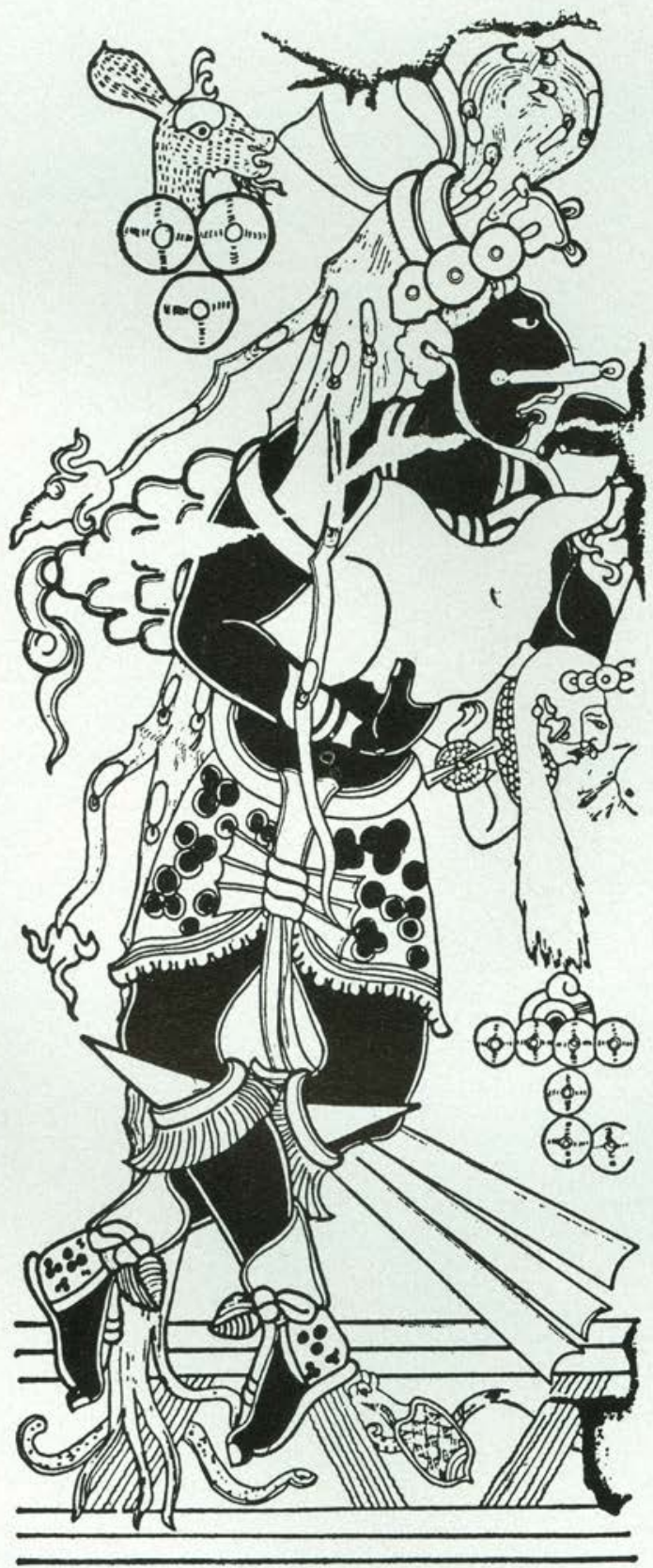

Figure 3. Line drawing of the southern Jamb painting (from Molina 1976b). 